\title{
Reference values for peak flow and FEV1 variation in healthy schoolchildren using home spirometry
}

\author{
A.F.J. Brouwer*, , R.J. Roorda*, , E.J. Duiverman" and P.L.P. Brand*
}

ABSTRACT: Current reference values for diurnal peak flow variation in healthy children (median 8.2\%; 95th percentile $31 \%$ ) are so high that considerable overlap exists with those of asthmatic children. These values have been obtained using written peak flow diaries, which are unreliable. The aim of the present study was to obtain reliable reference values for the variation in peak flow and forced expiratory volume in one second $\left(F E V_{1}\right)$ in healthy schoolchildren using home spirometry with electronic data storage.

Healthy schoolchildren ( $n=204 ; 100$ males) aged 6-16 yrs measured their peak flow and FEV1 twice daily for 2 weeks using an electronic home spirometer. The variation in peak flow and FEV 1 were calculated as a diurnal amplitude as a percentage of the day's mean.

The mean peak flow variation was $6.2 \%$ (95th percentile $12.3 \%$ ) and the mean FEV 1 variation was $5.7 \%$ (95th percentile $11.8 \%$ ).

Using home spirometry with electronic data storage, healthy schoolchildren show considerably less peak flow and forced expiratory volume in one second variation than previously reported on the basis of written peak flow diaries. Being the 95th percentiles of the distributions in healthy children, a peak flow variation of $\mathbf{1 2 . 3} \%$ and an forced expiratory volume in one second variation of $11.8 \%$ are suggested as cut-off values for disease when using home spirometry.

KEYWORDS: Forced expiratory volume in one second, home spirometry, peak flow variation, reference values, schoolchildren

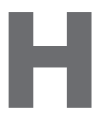
ome monitoring of peak expiratory flow $(\mathrm{PEF})$ is advocated in international guidelines for the management of asthma in children and adults [1]. Since PEFs are highly variable between patients, the patient's personal best value and diurnal variation in PEF are used in asthma guidelines, rather than age- and sexdependent PEF reference values [2-5].

Studies have shown a strong correlation between airway hyperresponsiveness and diurnal PEF variation in children with asthma [6, 7]. Therefore, variation in PEF is considered to be a measure of asthma severity [1, 2], and a diurnal variation in PEF of $>15-20 \%$ is considered increased. There is, however, only limited evidence to support this cut-off point $[1,2,8,9]$. The only published reference values for PEF variation were obtained using mechanical PEF meters with written diaries and showed high levels of PEF variation in healthy children, with a median of $8.2 \%$ and a 95th percentile of as high as $31 \%$ [9]. As a result, PEF variation is regarded to be of limited use in the diagnosis of asthma in children [1].
More recently, it has been shown that recording PEF using written diaries yields unreliable data and electronic recording was advocated [10-12]. Since the previously published PEF variation reference values were obtained using written PEF diaries [9], it is likely that they are unreliable. Children show high adherence to electronic home spirometry and perform these measurements in a technically correct manner [13-15]. The present authors hypothesised that values in records of diurnal variation in lung function in healthy schoolchildren obtained by electronic home spirometry would be lower than those recorded using unreliable written diaries of measurements from mechanical devices. Therefore, the present study was designed to obtain new reference values for PEF variation and forced expiratory volume in one second (FEV1) variation in healthy schoolchildren using such a home spirometer with electronic data

\section{METHODS}

Healthy peers, aged 6-16 yrs, of children with asthma visiting an outpatient clinic (Isala Clinics, storage under field conditions.

\section{AFFILIATIONS}

*Princess Amalia Children's Clinic, Isala Clinics, Zwolle

\#Dept of Paediatric Pulmonology, University of Groningen/University Medical Center, Beatrix Children's Hospital, Groningen, and

- St Anna Care Group, Geldrop, the Netherlands.

\section{CORRESPONDENCE}

A.F.J. Brouwer

University of Groningen/University Medical Center

Dept of Paediatric Pulmonology

Beatrix Children's Hospital

P.0. Box 30.001

9700 VB Groningen

The Netherlands

Fax: 31503611704

E-mail: brouwerafj@bkk.umcg.nl

Received:

November 062007

Accepted after revision:

April 062008

SUPPORT STATEMENT

This study was supported by the Foundation for Asthma Treatment (The Hague, the Netherlands), who had no involvement in: the study design; the collection, analysis and interpretation of data; the writing of the report; or the decision to submit the article for publication.

STATEMENT OF INTEREST

A statement of interest for R.J. Roorda and for the study itself can be found at www.erj.ersjournals.com/ misc/statements.shtml 
Zwolle, the Netherlands) were recruited. Children were excluded if they had: 1) a recent or chronic disease of the respiratory tract, or a history of chronic respiratory disease; 2 ) a history of severe respiratory disease, e.g. congenital lung disease, hospitalisation for pneumonia or surgery of the thorax; 3) systemic disease with direct or indirect influence on the respiratory tract, e.g. neuromuscular disorders; 4) other chronic or acute disease with influence on the respiratory tract; 5) use of inhaled corticosteroids, bronchodilators or other medicines influencing the respiratory tract; and 6) household exposure to tobacco smoke [16].

In order to obtain PEF and FEV1 variation data from different age groups and sexes, the intention was to include four groups, each of $>50$ children: males aged 6-11 yrs, males aged 1216 yrs, females aged $6-11$ yrs, and females aged $12-16$ yrs. The total number of 200 participants was preset empirically based on previously published normative data studies concerning respiratory disease in childhood [17-20]. The age groups were formed to represent primary versus secondary schoolchildren.

At the start of the study, the children performed flow-volume curve manoeuvres, in a pulmonary function laboratory (Isala Clinics), using a Jaeger Masterlab pneumotachograph (Erich Jaeger, Würzburg, Germany) following American Thoracic Society (ATS)/European Respiratory Society (ERS) guidelines for the measurement of lung function [5]. Children were excluded if their FEV1 was $<80 \%$ of the predicted value or the flow-volume curve had an abnormal shape $[5,21]$.

After inclusion, patients were instructed how to use the electronic home spirometer (Koko Peak Pro; Ferraris Respiratory, Louisville, CO, USA) [1,5]. This portable home spirometer has been designed to measure PEF and FEV1 under field conditions without the need for repeated calibration. It has been validated using a precision waveform generator, demonstrating its agreement with performance standards as recommended by international guidelines [5, 22], as well as in children with asthma in the same age group [23]. Patients were instructed to perform three forced expiratory flow manoeuvres twice daily at home between 06:00 and 10:00 $\mathrm{h}$ and between 18:00 and 22:00 $\mathrm{h}$ throughout a 2-week study period. All instructions were given by the same experienced technician, encouraging the children to obtain optimal lung function values, and at least one parent attended the instruction session. Patients were instructed to achieve PEF as rapidly as possible and to continue the manoeuvre for $\geqslant 2 \mathrm{~s}$. An integrated quality check warned the user when a cough was detected, the blow was not long enough or there was a slow start. The device then showed an exclamation mark and children were asked to repeat their measurements. During analyses, measurements were only accepted if forced vital capacity exceeded FEV1. The device automatically stored the highest of the three correctly performed PEF measurements on a microchip, along with the accompanying FEV1, labelled with the time and date of measurement.

Following the 2-week study period, the device was returned and all records were downloaded on to a computer. Adherence to home spirometry measurements was expressed as the percentage of days with two usable recordings (one in the morning and one in the evening) [24]. Diurnal variation in PEF (in litres per minute) and in FEV1 (in litres) were expressed as the absolute amplitude (maximum to minimum) as a percentage of the day's absolute mean, and day-to-day variation in PEF and FEV1 were expressed as the absolute amplitude (maximum to minimum) of the morning measurements as a percentage of their absolute mean [25]. All data were analysed applying standard parametric and nonparametric tests as appropriate [26]. The present study was approved by the Medical and Ethical Judging Committee of Isala Clinics, and study subjects and parents gave written informed consent. The reference values for PEF and FEV1 variation obtained in the present population of healthy schoolchildren were compared to previously published results obtained in a sample of asthmatic schoolchildren over a 2-week period [14]. The home spirometer used, the instructions and procedures for recording PEF and FEV1 at home, and the analyses of the data were identical between the two studies.

\section{RESULTS}

Healthy children aged 6-16 yrs $(n=205)$ were included in the present study. After inclusion, one child was excluded because of abnormal lung function results and an abnormal flowvolume curve (FEV1 $<80 \%$ pred and curve concavity) at the start of the study, despite the absence of respiratory symptoms. Each predefined group consisted of $\geqslant 50$ children, with a minimum of 13 children per age year group. The characteristics of these groups are shown in table 1.

The median adherence to home spirometry was $86 \%$, with no significant difference between groups and a small but significant difference between the first and last week for the total study group ( 87 versus $82 \% ; \mathrm{p}<0.0001$ ). The mean diurnal and day-to-day variations (with their 95th percentiles) in PEF and FEV1, respectively, of the four groups are shown in tables 2 and 3.

Children aged 6-11 yrs exhibited significantly higher variations in PEF (95\% confidence interval (CI) for difference 0.9$2.5 \% ; \mathrm{p}<0.0001)$ and $\mathrm{FEV} 1$ (95\% CI for difference $0.5-2.0 \%$; $\mathrm{p}=0.002)$ than children aged 12-16 yrs. There were no significant differences in variation in PEF or FEV1 between males and females, nor between the first and last week of measurements. Figure 1 shows the diurnal variation in PEF

\begin{tabular}{|c|c|c|c|c|}
\hline & \multicolumn{2}{|c|}{$6-11 \mathrm{yr}$ olds } & \multicolumn{2}{|c|}{$12-16$ yr olds } \\
\hline & Female & Male & Female & Male \\
\hline Participants n & 51 & 50 & 53 & 50 \\
\hline Age yrs & $8.4 \pm 1.7$ & $8.8 \pm 1.6$ & $13.8 \pm 1.4$ & $13.7 \pm 1.1$ \\
\hline \multicolumn{5}{|c|}{ Pneumo. \% pred } \\
\hline FEV 1 & $105.0 \pm 11.9$ & $103.9 \pm 12.2$ & $106.1 \pm 10.9$ & $98.5 \pm 11.1$ \\
\hline FVC & $98.2 \pm 11.1$ & $98.9 \pm 11.1$ & $98.3 \pm 11.4$ & $92.8 \pm 10.2$ \\
\hline MEF50 & $90.7 \pm 20.3$ & $88.7 \pm 18.5$ & $99.7 \pm 19.2$ & $93.7 \pm 20.7$ \\
\hline
\end{tabular}

Data are presented as mean \pm SD, unless otherwise stated. Pneumo pneumotachography; \% pred: \% predicted; FEV1: forced expiratory volume in one second; FVC: forced vital capacity; MEF50: mean expiratory flow when $50 \%$ of the FVC remains to be exhaled. 


\begin{tabular}{|c|c|c|c|c|c|}
\hline & \multirow[t]{3}{*}{ Subjects $\mathrm{n}$} & \multicolumn{4}{|c|}{ Amplitude of variation $\%$ mean } \\
\hline & & \multicolumn{2}{|c|}{ PEF } & \multicolumn{2}{|c|}{ FEV $_{1}$} \\
\hline & & Mean $(95 \% \mathrm{Cl})$ & 95th percentile & Mean $(95 \% \mathrm{Cl})$ & 95th percentile \\
\hline Male & 50 & $6.9(6.1-7.7)$ & 10.4 & $6.6(5.8-7.4)$ & 9.8 \\
\hline \multicolumn{6}{|c|}{$12-16$ yr olds } \\
\hline Female & 53 & $5.8(5.0-6.7)$ & 12.2 & $5.2(4.5-5.9)$ & 8.5 \\
\hline Male & 50 & $4.9(4.3-5.6)$ & 8.0 & $5.1(4.3-6.0)$ & 8.5 \\
\hline Total & 204 & $6.2(5.8-6.7)$ & 12.3 & $5.7(5.4-6.1)$ & 11.8 \\
\hline
\end{tabular}

and FEV1 per yr of age and illustrates the slightly decreasing variation in PEF with increasing age. Both PEF and FEV1 variation were independent of height and weight. Selfreported atopy was only present in six children. Exclusion of these six children did not change the outcome. None of the children showed a variation in PEF or FEV1 of $>20 \%$. The overall mean diurnal PEF variation for healthy children aged 6-16 yrs was 6.2\% (95\% CI 5.8-6.7\%; 95th percentile $12.3 \%$ ) and the overall mean diurnal FEV1 variation was 5.7\% (95\% CI 5.4$6.1 \%$; 95 th percentile $11.8 \%$ ). The mean \pm SD absolute difference between morning and evening PEF was $18.9 \pm 9.0 \mathrm{~L} \cdot \mathrm{min}^{-1}(95 \%$ CI $\left.17.7-20.2 \mathrm{~L} \cdot \mathrm{min}^{-1}\right)$, and the mean absolute difference between morning and evening FEV1 was 0.13 $\pm 0.07 \mathrm{~L}(95 \%$ CI $0.12-0.14 \mathrm{~L}$ ). The diurnal differences between the age groups are presented in table 4 .

Of the healthy children, $76 \%$ exhibited lower morning than evening PEFs, suggesting a similar circadian rhythm to that seen in asthmatic children [27]. However, only $48 \%$ of the healthy children showed lower morning than evening FEV1.
The previously published asthmatic group consisted of 36 well-controlled asthmatic children ( 25 males) with a mean age of $10.4 \mathrm{yrs}$ [14]. In all of the children, the diagnosis was confirmed by a paediatric pulmonologist, and all were using maintenance treatment with inhaled corticosteroids. Their lung function characteristics are shown in table 5.

Figure 2 shows the differences in PEF and FEV1 variation between the well-controlled asthmatic children of the previously conducted study [14] and the present healthy children. The differences were significant for both diurnal PEF variation $(p=0.001)$ and diurnal FEV1 variation $(p<0.0001)$, with mean differences of $1.4 \%$ (95\% CI $0.3-2.5 \%$ ) and $2.7 \%$ (95\% CI $1.6-$ 3.8), respectively. There was considerable overlap between the healthy children and the well-controlled asthmatics for both variables (fig. 2). The range of mean amplitude of diurnal PEF variation and diurnal FEV1 variation in the asthmatic group was $3.5-24.3 \%$ mean and $2.8-26.4 \%$ mean for PEF and FEV1, respectively, during the first 2 weeks of the study. Of the asthmatic children, $24(62 \%)$ showed a diurnal PEF variation of

\begin{tabular}{|c|c|c|c|c|c|}
\hline & \multirow[t]{3}{*}{ Subjects $\mathrm{n}$} & \multicolumn{4}{|c|}{ Amplitude of variation $\%$ mean } \\
\hline & & \multicolumn{2}{|c|}{ PEF } & \multicolumn{2}{|c|}{ FEV 1} \\
\hline & & Mean $(95 \% \mathrm{Cl})$ & 95th percentile & Mean $(95 \% \mathrm{Cl})$ & 95th percentile \\
\hline Female & 51 & $7.3(6.1-8.4)$ & 12.2 & $7.1(5.7-8.7)$ & 13.2 \\
\hline Male & 50 & $6.8(6.1-7.6)$ & 11.3 & $7.0(6.0-7.9)$ & 11.3 \\
\hline \multicolumn{6}{|c|}{$12-16$ yr olds } \\
\hline Female & 53 & $5.8(5.1-6.5)$ & 8.7 & $5.3(4.7-6.0)$ & 8.6 \\
\hline Male & 50 & $5.2(4.4-5.9)$ & 9.5 & $4.8(3.9-5.7)$ & 8.7 \\
\hline
\end{tabular}



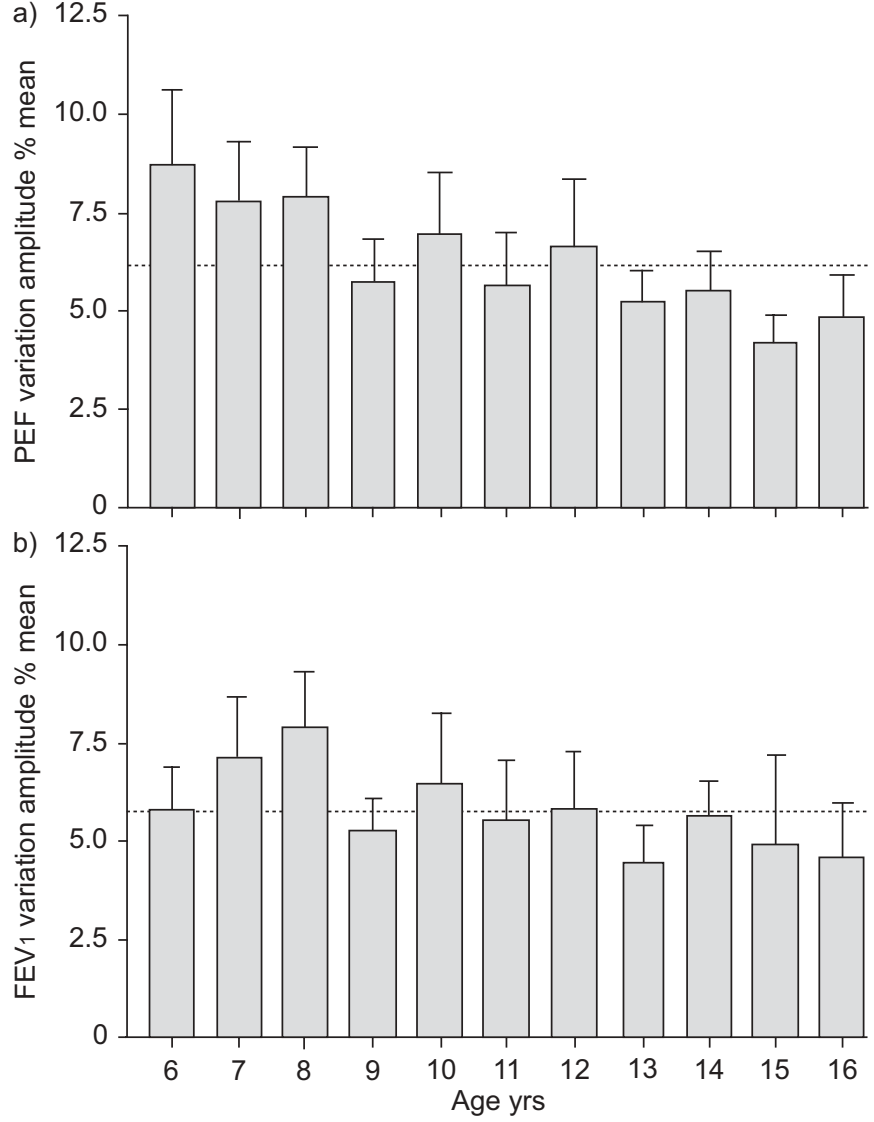

FIGURE 1. Variation in a) peak expiratory flow (PEF) and b) forced expiratory volume in one second (FEV1). Data are presented as means (……..: overall mean). Vertical bars represent the $95 \%$ confidence interval. Variations are reasonably consistent between the different age groups, with a trend towards a lower variation in PEF in the older children. Single reference values for variation in PEF and in FEV1 are possible.

$>12.3 \%$ or a diurnal FEV1 variation of $>11.8 \%$, the overall 95 th percentile of the healthy group of schoolchildren in any given week of the total 3-month study period.

\section{DISCUSSION}

The present study shows that, using home spirometry, healthy children exhibit substantially lower variation in lung function than previously described with mechanical PEF meters [9]. Since the previously described reference values were obtained using unreliable written PEF diaries [10,11], the present study used validated home spirometers with electronic data storage, generating more reliable reference values for variation in PEF and FEV1 [12]. There were no differences between male and female children. Although younger children showed significantly higher variation in PEF and FEV1 than older children (table 2; fig. 1), this difference was considered too small and too variable to be of clinical relevance. Since PEF and FEV1 variation were not dependent upon height or weight, and the influence of age was negligible, all data from the participating children were pooled to give a single reference value for variation in lung function for all ages and sexes. Only two $(<1 \%)$ subjects showed PEF or FEV1 variation of $>15 \%$, and none of $>20 \%$. The day-to-day variation data gave similar

\begin{tabular}{|c|c|c|c|}
\hline \multirow[t]{2}{*}{ TABLE 4} & \multicolumn{3}{|c|}{$\begin{array}{l}\text { Diurnal differences in peak expiratory flow (PEF) } \\
\text { and forced expiratory volume in one second } \\
\left(F_{1} V_{1}\right) \text { using home spirometry with electronic } \\
\text { data storage }\end{array}$} \\
\hline & Subjects $n$ & PEF L. $\min ^{-1}$ & FEV 1 L \\
\hline \multicolumn{4}{|l|}{$6-11$ yr olds } \\
\hline Female & 51 & $16.4 \pm 5.6(14.8-18.0)$ & $0.10 \pm 0.04(0.09-0.11)$ \\
\hline Male & 50 & $17.5 \pm 7.7(15.4-19.7)$ & $0.12 \pm 0.06(0.11-0.14)$ \\
\hline \multicolumn{4}{|c|}{$12-16$ yr olds } \\
\hline Female & 53 & $23.5 \pm 13.0(19.9-27.1)$ & $0.16 \pm 0.08(0.13-0.18)$ \\
\hline Male & 50 & $18.2 \pm 5.8(16.5-19.8)$ & $0.14 \pm 0.09(0.12-0.17)$ \\
\hline
\end{tabular}

Data are presented as mean \pm SD (95\% confidence interval), unless otherwise stated.

results, also lower than those previously published [9], showing the stability of lung function measurements throughout the study. The present authors propose that the 95th percentiles from the present study, i.e. $12.3 \%$ for PEF variation and $11.8 \%$ for FEV1 variation, be used as new reference values for diurnal variation in lung function in schoolchildren when using home spirometry under field conditions.

The reference values for PEF and FEV1 variation in healthy schoolchildren were significantly lower than those recorded in a group of asthmatic schoolchildren with chronic persistent, but clinically stable, asthma (fig. 2). This suggests that home spirometry might be a useful diagnostic tool in the differentiation of asthmatic and nonasthmatic children. However, it should be emphasised that these results were obtained in selected groups of clearly healthy children on the one hand and children with a firm diagnosis of chronic persistent asthma who were diagnosed and followed-up in a specialised clinic on the other. Whether home spirometry will be a useful tool for ruling out or diagnosing asthma in children with nonspecific chronic respiratory symptoms remains to be evaluated in a separate study.

Some limitations of the present study should be discussed. First, the present study population was not a random population sample. For practical reasons, healthy schoolchildren were recruited by asking asthmatic children to approach their healthy peers to participate. By applying strict exclusion criteria, which have proven useful in the selection of healthy subjects for obtaining lung function reference values [16], the present selection of healthy children should be representative of healthy nonasthmatic children. The application of these strict exclusion criteria precludes examination of the influence of passive smoke exposure on the present reference values. In studies using mechanical PEF meters and written diaries, diurnal PEF variation was up to $10 \%$ higher in children exposed to tobacco smoke [28]. Although this suggests that variation in PEF and FEV1 recorded by home spirometry may be higher in healthy children of smoking parents than the values reported herein, this should be substantiated by further studies. Owing to the low prevalence of atopy in the present study cohort, it was not possible to examine its influence on PEF and FEV1 variation in a meaningful way. 


\begin{tabular}{lc} 
TABLE 5 & Characteristics of the 36 asthmatic children \\
\hline Log PD20 $\boldsymbol{\mu g}$ & $1.98(1.28-2.91)$ \\
FEV1 \% pred & $99.1 \pm 12.6$ \\
FVC \% pred & $98.0 \pm 8.6$ \\
MEF50 \% pred & $79.7 \pm 21.7$ \\
\hline & \\
Data are presented as median (interquartile range) or mean \pm SD. PD20: pro- \\
vocative dose of methacholine causing a 20\% fall in forced expiratory volume in \\
one second (FEV1); \% pred: \% predicted; FVC: forced vital capacity; MEF50: \\
mean expiratory flow when 50\% of the FVC remains to be exhaled. Data from [14].
\end{tabular}

Secondly, the reference values were obtained using only one type of portable home spirometer. It is possible that the use of a different device may have rendered different results. It is unlikely, however, that this is clinically relevant. All home spirometers are designed for the same purpose, namely measuring lung function under field conditions, without the need for repeated calibration. All comply with ATS/ERS guidelines and have to be validated using computer-generated waveforms [5]. Although small differences between measurements obtained with home spirometers and hospital pneumotachographs have been found [23, 29-31], manoeuvre reproducibility using home spirometry has been shown to be acceptable for a reliable calculation of variation in lung function [13, 23]. In addition, although there is increasing evidence that younger children are able to exhale their complete vital capacity in $<1 \mathrm{~s}$ [32], the younger children in the present study showed that they could perform reliable FEV1 measurements during the instruction sessions, and a maximum of only two measurements per child were excluded from analyses for this reason (data not shown). Furthermore, the children were warned by the device during the measurement when a blow was too short and then repeated the measurement correctly. Therefore, it is likely that the present reference values for PEF and FEV1 variation are also applicable with other home spirometers.

Finally, the technical quality of the forced expiratory manoeuvre was only checked during the instruction session at the start of the study and was not assessed at home. However, as previously mentioned, a quality check is integrated into the home spirometer, warning the user, via an exclamation mark on the screen, if a manoeuvre is incorrectly performed. More importantly, other studies have shown that children generate high-quality lung function data using home spirometry under field conditions after careful instruction [13, 15]. This was also the case in the present study. Subjects recorded two usable recordings on $>85 \%$ of days and showed no deterioration in PEF and FEV1 variation over time. Furthermore, these reference values will be used in similar circumstances in clinical practice. Therefore, the present authors are confident that the reference values obtained for PEF and FEV1 variation are of high quality and can be used in clinical practice and research.

To the current authors' knowledge, the present reference values are the first values published for variation in both PEF and FEV1 using home spirometry with electronic data storage. Since the FEV1 is considered to reflect the patency of intrathoracic airways more reliably than PEF and is less effort-dependent [2, 5],

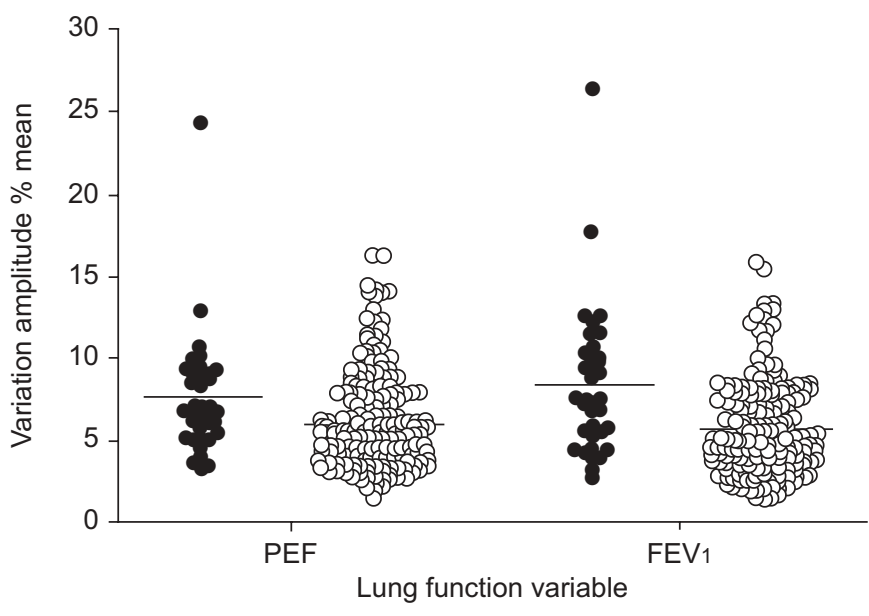

FIGURE 2. Variation in peak expiratory flow (PEF) and forced expiratory volume in one second $\left(F E V_{1}\right)$ in asthmatic $(\bullet)$ and healthy children $(\bigcirc)$. Horizontal bars represent means. Although the means of both groups are significantly different for both PEF and FEV1, there is considerable overlap between healthy children and well-controlled asthmatics. Data for asthmatic children from [14].

FEV1 may well be a more useful measure of lung function in children than PEF. Although monitoring lung function at home is advocated in guidelines on the long-term management of asthma, studies have consistently shown that such home monitoring of lung function and according modification of long-term treatment does not improve asthma control or outcome [33-36]. As a result, the present authors would not encourage the use of the current reference values in asthma selfmanagement. The present authors believe, however, that the current study results support the hypothesis that home spirometry might be used as a diagnostic tool for childhood asthma in children with chronic wheeze, cough or dyspnoea, when history, physical examination and office spirometry are insufficient to make or exclude the diagnosis reliably. This hypothesis will have to be tested in a study specifically designed to that end. The use of PEF diaries to distinguish asthmatic from nonasthmatic children has been largely abandoned as previous studies showed almost complete overlap of PEF variation between asthmatic [6,7] and healthy children, with a 95th percentile of as high as 31\% for PEF variation in healthy children [9]. It is now deemed highly likely that these reference values were spuriously high because they were obtained using unreliable written PEF diaries. If the present reference values for PEF and FEV1 variation are compared to the levels of such variation in well-controlled asthmatic children using an electronic home spirometer as a monitoring tool, there is much less overlap of variation in lung function between healthy children and children with asthma, even when the latter were using inhaled corticosteroids [10, 13, 14]. For example, in the previously published study of well-controlled asthmatic children using inhaled corticosteroids, $62 \%$ showed a PEF variation of $>12.3 \%$ in any given week during a 3-month study period, using the same home spirometer [14], despite (near-) normal lung function (table 5). Given the fact that inhaled corticosteroids reduce PEF variation considerably $[6,7]$, it is highly likely that even more symptomatic asthmatic children would show a variation in lung function above the present reference values when they are not using inhaled corticosteroids. Prospective 
studies, however, are needed to examine the diagnostic value of home spirometry for the identification of asthma in children in whom history and physical examination are insufficiently helpful in ruling asthma in or out as the cause of chronic respiratory symptoms.

In conclusion, the 95th percentiles of variation in peak expiratory flow and forced expiratory volume in one second in healthy schoolchildren, using home spirometers with electronic data storage, are 12.3 and $11.8 \%$, respectively. This is considerably lower than previously reported reference values for peak expiratory flow variation obtained using mechanical meters and written diaries, and reduces the amount of overlap between healthy and asthmatic children. Further prospective studies are required in order to investigate whether or not home spirometry could be a useful diagnostic tool for childhood asthma.

\section{REFERENCES}

1 Global Initiative for Asthma, Global Strategy for Asthma Management and Prevention. www.ginasthma.com/ Guidelineitem.asp? $11=2 \& 12=1$ \&intId $=1388$ \&archived $=1$ Date last updated: 2006. Date last accessed: 4 July 2008.

2 Quanjer PH, Lebowitz MD, Gregg I, et al. Peak expiratory flow: conclusions and recommendations of a Working Party of the European Respiratory Society. Eur Respir J 1997; 10: Suppl. 24, 2s-8s.

3 Carson JW, Hoey H, Taylor MR. Growth and other factors affecting peak expiratory flow rate. Arch Dis Child 1989; 64: 96-102.

4 Taylor MRH. Asthma: audit of peak flow rate guidelines for admission and discharge. Arch Dis Child 1994; 70: 432-434.

5 Miller MR, Hankinson J, Brusasco V, et al. Standardisation of spirometry. Eur Respir J 2005; 26: 319-338.

6 Brand PLP, Duiverman EJ, Waalkens HJ, et al. Peak flow variation in childhood asthma: correlation with symptoms, airways obstruction, and hyperresponsiveness during long-term treatment with inhaled corticosteroids. Thorax 1999; 54: 103-107.

7 Brand PLP, Duiverman EJ, Postma DS, et al. Dutch CNSLD Study Group. Peak flow variation in childhood asthma: relationship to symptoms, atopy, airways obstruction and hyperresponsiveness. Eur Respir J 1997; 10: 1242-1247.

8 Lebowitz MD, Krzyzanowski M, Quackenboss JJ, et al. Diurnal variation of PEF and its use in epidemiological studies. Eur Respir J 1997; 10: Suppl. 24, 49s-56s.

9 Quackenboss JJ, Lebowitz MD, Krzyzanowski M. The normal range of diurnal changes in peak expiratory flow rates. Relationship to symptoms and respiratory disease. Am Rev Respir Dis 1991; 143: 323-330.

10 Redline S, Wright EC, Kattan M, et al. Short-term compliance with peak flow monitoring: results from a study of inner city children with asthma. Pediatr Pulmonol 1996; 21: 203-210.

11 Kamps AW, Roorda RJ, Brand PLP. Peak flow diaries in childhood asthma are unreliable. Thorax 2001; 56: 180-182.

12 Sly PD, Flack F. Is home monitoring of lung function worthwhile for children with asthma? Thorax 2001; 56: 164-165.

13 Thompson R, Delfino RJ, Tjoa T, et al. Evaluation of daily home spirometry for school children with asthma: new insights. Pediatr Pulmonol 2006; 41: 819-828.
14 Brouwer AFJ, Roorda RJ, Brand PLP. Home spirometry and asthma severity in children. Eur Respir J 2006; 28: 1131-1137.

15 Wensley DC, Silverman M. The quality of home spirometry in school children with asthma. Thorax 2001; 56: 183-185.

16 Taussig LM, Chernick V, Wood R, et al. Standardization of lung function testing in children. Proceedings and Recommendations of the GAP Conference Committee, Cystic Fibrosis Foundation. J Pediatr 1980; 97: 668-676.

17 Malmberg LP, Petäys T, Haahtela T, et al. Exhaled nitric oxide in healthy nonatopic school-age children: determinants and height-adjusted reference values. Pediatr Pulmonol 2006; 41: 635-642.

18 Baraldi E, Azzolin NM, Cracco A, et al. Reference values of exhaled nitric oxide for healthy children 6-15 years old. Pediatr Pulmonol 1999; 27: 54-58.

19 Klug B, Bisgaard H. Specific airway resistance, interrupter resistance, and respiratory impedance in children aged 27 years. Pediatr Pulmonol 1998; 25: 322-331.

20 Arets HG, Brackel HJ, van der Ent CK. Applicability of interrupter resistance measurements using the MicroRint in daily practice. Respir Med 2003; 97: 366-374.

21 Zapletal A, Paul T, Samanek M. Normal values of static pulmonary volumes and ventilation in children and adolescents. Cesk Pediatr 1976; 31: 532-539.

22 Ferraris Respiratory. KoKo Peak Pro 6. PEF, FEV1, FEV6 and FEV1/FEV6 Meter: www.quickmedical.com/pdf/ferraris/ koko_peak_literature.pdf Date last accessed: 4 July 2008.

23 Brouwer AFJ, Roorda RJ, Brand PLP. Comparison between peak expiratory flow and FEV1 measurements on a home spirometer and on a pneumotachograph in children with asthma. Pediatr Pulmonol 2007; 47: 813-818.

24 Brouwer AFJ, Brand PLP, Roorda RJ. A pitfall in calculating the adherence in home spirometry. Eur Respir J 2006; 28: Suppl. 50, 476s.

25 Jain P, Kavuru MS, Emerman CL, et al. Utility of peak expiratory flow monitoring. Chest 1998; 114: 861-876.

26 Altman DG, Machin D, Bryant T, et al., Statistics with Confidence. 2nd Edn. London, BMJ Books, 2002..

27 Vargas $\mathrm{MH}$, Ruiz-Gutiérrez $\mathrm{HH}$, Espinosa-Serafin C, Zúñiga-Vázquez G, Furuya ME, Underestimation of the peak flow variation in asthmatic children: evaluation of a new formula. Pediatr Pulmonol 2005; 39: 325-331.

28 Cook DG, Strachan DP. Parental smoking, bronchial reactivity and peak flow variability in children. Thorax 1998; 53: 295-301.

29 Mortimer KM, Fallot A, Balmes JR, et al. Evaluating the use of a portable spirometer in a study of pediatric asthma. Chest 2003; 123: 1899-1907.

30 Bastian-Lee Y, Chavasse R, Richter H, et al. Assessment of a low-cost home monitoring spirometer for children. Pediatr Pulmonol 2002; 33: 388-394.

31 Godschalk I, Brackel HJ, Peters JC, et al. Assessment of accuracy and applicability of a portable electronic diary card spirometer for asthma treatment. Respir Med 1996; 90: 619-622.

32 Crenesse D, Berlioz M, Bourrier T, Albertini M. Spirometry in children aged 3 to 5 years: reliability of forced expiratory maneuvers. Pediatr Pulmonol 2001; 32: 56-61.

33 Reddel H, Jenkins C, Woolcock A. Diurnal variability time to change the guidelines? BMJ 1999; 319: 45-47. 
34 Brand PLP, Roorda RJ. Usefulness of monitoring lung function in asthma. Arch Dis Child 2003; 88: 1021-1025.

35 Wensley D, Silverman M. Peak flow monitoring for guided self-management in childhood asthma: a randomized controlled trial. Am J Respir Crit Care Med 2004; 170: 606-612.
36 Turner MO, Taylor D, Bennett $\mathrm{R}$, et al. A randomized trial comparing peak expiratory flow and symptom selfmanagement plans for patients with asthma attending a primary care clinic. Am J Respir Crit Care Med 1998; 157: 540-546. 